\title{
Synthesis and Thermal Study of Hexacoordinated Aluminum(III) Triazenides for Use in Atomic Layer Deposition
}

\author{
Rouzbeh Samii, David Zanders, Sydney C. Buttera, Vadim Kessler, Lars Ojamäe, Henrik Pedersen, \\ and Nathan J. O’Brien*
}

Cite This: Inorg. Chem. 2021, 60, 4578-4587

Read Online

ACCESS | Lill Metrics \& More | 国 Article Recommendations ｜ st Supporting Information

ABSTRACT: Amidinate and guanidinate ligands have been used extensively to produce volatile and thermally stable precursors for atomic layer deposition. The triazenide ligand is relatively unexplored as an alternative ligand system. Herein, we present six new $\mathrm{Al}$ (III) complexes bearing three sets of a 1,3-dialkyltriazenide ligand. These complexes volatilize quantitatively in a single step with onset volatilization temperatures of $\sim 150{ }^{\circ} \mathrm{C}$ and 1 Torr vapor pressures of $\sim 134{ }^{\circ} \mathrm{C}$. Differential scanning calorimetry revealed that these $\mathrm{Al}(\mathrm{III})$ complexes exhibited exothermic events that overlapped with the temperatures of their mass loss events

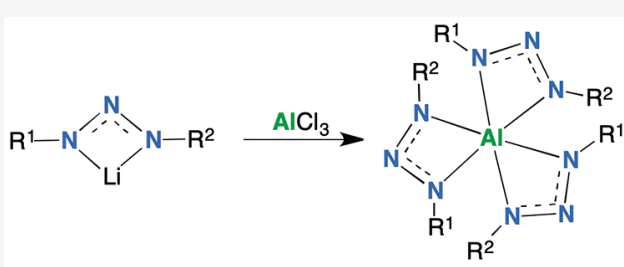
$R^{1}, R^{2}=\mathbb{P r}, s B u, t B u$ $\mathrm{Al}\left(\mathrm{R}^{1} \mathrm{~N}_{3} \mathrm{R}^{2}\right)_{3}$ in thermogravimetric analysis. Using quantum chemical density functional theory computations, we found a decomposition pathway that transforms the relatively large hexacoordinated $\mathrm{Al}$ (III) precursor into a smaller dicoordinated complex. The pathway relies on previously unexplored interligand proton migrations. These new $\mathrm{Al}(\mathrm{III})$ triazenides provide a series of alternative precursors with unique thermal properties that could be highly advantageous for vapor deposition processes of $\mathrm{Al}$ containing materials.

\section{INTRODUCTION}

Aluminum nitride (AlN) is a semiconductor material widely used in current day electronic devices. ${ }^{1}$ This is due to its desirable chemical, optical, and electronic properties, such as high thermal stability, a wide direct band gap, and piezoelectricity. ${ }^{2}$ As electronic devices rapidly miniaturize with increasingly complex surface structures, atomic layer deposition (ALD) becomes a vital technique for depositing uniform thin films of high-performance materials for future microelectronics. ${ }^{3}$ In ALD, the metal and nonmetal precursors are introduced into the reaction chamber separately, which allows the film mechanism to be governed by two independent and self-limiting half reactions. These are complex surface reactions that can incorporate impurities into the film if the metal precursor does not possess suitable physical and chemical properties. A desirable ALD metal precursor must be thermally stable until reaching the film surface. ${ }^{4}$ Here, it should undergo a clean and fast reaction to form a single stable monolayer without trapping unwanted byproducts. ${ }^{3}$ This monolayer should then react with the second precursor (e.g., $\mathrm{NH}_{3}$ or $\mathrm{H}_{2} \mathrm{O}$ ) in the same way. To maximize the growth rate of a thin film, a precursor must be sufficiently volatile and have ligands of low steric bulk for fast surface saturation and maximum density of the deposited precursor. Due to its high volatility and reactivity, trimethylaluminum $\left(\mathrm{AlMe}_{3}\right)$ has been used to deposit AlN by ALD. ${ }^{5-13}$ These films contain high levels of carbon impurities due to the strong $\mathrm{Al}-\mathrm{C}$ bonds, making it difficult to remove all of the methyl ligands of the deposited precursor at low temperatures. ${ }^{5,6}$ Replacing the $\mathrm{Al}-\mathrm{C}$ of $\mathrm{AlMe}_{3}$ with more reactive $\mathrm{Al}-\mathrm{N}$ bonds has led to homoleptic tricoordinated amide precursors $\left(\mathrm{Al}\left(\mathrm{NMe}_{2}\right)_{3}\right)^{14}$ and $(\mathrm{Al}-$ $\left.\left(\mathrm{NEt}_{2}\right)_{3}\right),{ }^{15}$ which have been used to deposit AlN by ALD. ${ }^{16-19}$ Although these precursors are highly volatile and reactive, the low thermal stability of the deposited surface species renders films with carbon impurities. ${ }^{20}$

Amidinate and guanidinate bidentate ligands have been employed to improve thermal stability of group 13 metal precursors. Although these ligands improve thermal stability in comparison to monodentate ligated precursors, their drawback is compounds that lack volatility or surface reactivity, or both, the latter due to crowding of the metal center. ${ }^{21-27}$ In particular, homoleptic hexacoordinated $\mathrm{M}-\mathrm{N}$ bonded $\mathrm{Al}(\mathrm{III})$ amidinate $\left(\mathrm{Al}(\mathrm{amd})_{3}\right)$ and guanidinate $\left(\mathrm{Al}(\text { guan })_{3}\right)$ compounds possess increased thermal stability compared to tricoordinated $\mathrm{Al}(\mathrm{III})$ amides, ${ }^{2,27}$ but have not been used in an ALD process due to insufficient volatility. A ligand closely related to the amidinate and guanidinate is the triazenide, differing by the nitrogen atom in the endocyclic position of the ligand backbone. Homoleptic hexacoordinated $\mathrm{Al}$ (III) triazenide complexes have previously been reported; ${ }^{28,29}$ however, they are not volatile due to their 1,3-diphenyltriazenide ligands.

Received: December 1, 2020

Published: March 12, 2021 
Recently, we reported the first examples of highly volatile homoleptic 1,3-dialkyltriazenide complexes, tris(1,3diisopropyltriazenide) $\operatorname{In}(\mathrm{III})\left(\mathrm{In}(\mathrm{triaz})_{3}\right)^{30}$ and $\mathrm{Ga}$ (III) (Ga$\left.(\text { triaz })_{3}\right)^{31}$ and their use as ALD precursors. These new triazenide precursors underwent gas-phase decomposition at higher temperatures inside the ALD reactor, giving a smaller and more reactive $\mathrm{M}(\mathrm{III})$ species. This in situ thermolysis was highly advantageous for film growth, giving higher growth rates and films with near stoichiometric $\mathrm{M} / \mathrm{N}$ ratios without unwanted carbon impurities. To further explore the unique properties of the 1,3-dialkyltriazenide ligand, we envisaged its ability to stabilize the $\mathrm{Al}(\mathrm{III})$ center to develop a new series of precursors that can be used for future ALD processes. Herein, we describe the synthesis, structure, and thermal properties of six homoleptic Al(III) 1,3-dialkyltriazenide complexes. These compounds were easily synthesized in good yields and are the first example of volatile hexacoordinated $\mathrm{M}-\mathrm{N}$ bonded aluminum compounds. Furthermore, the compounds exhibit unique thermal properties, similar to $\mathrm{Ga}(\text { triaz })_{3}$ and $\operatorname{In}(\text { triaz })_{3}$. Using quantum-chemical density functional theory (DFT) calculations, we mapped out a previously unexplored decomposition pathway utilizing interligand interactions. The pathway is supported by electron impact mass spectrometry (EI-MS) data. The unique thermal properties of these compounds make them potentially advantageous as precursors for vapor deposition processes.

\section{RESULTS AND DISCUSSION}

2.1. Synthesis and Characterization of Aluminum Complexes. Tris(1,3-dialkyltriazenide)aluminum(III) compounds 1-6 were prepared in good yields by reacting the (1,3-dialkyltriazenide)lithium(I) intermediate, generated from an alkylazide ${ }^{32,33}$ and alkyllithium, with $\mathrm{AlCl}_{3}$ (Scheme 1). All

Scheme 1. Synthesis of Tris(1,3-

dialkyltriazenide)aluminum(III) Compounds 1-6

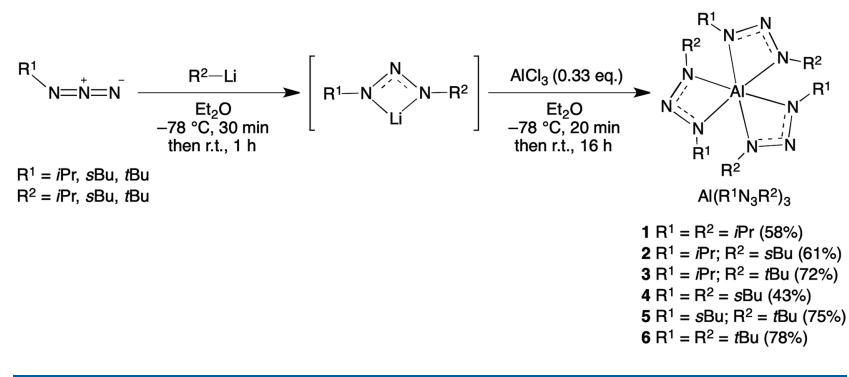

compounds were purified by recrystallization and were fully characterized by nuclear magnetic resonance (NMR) spectroscopy, elemental analysis (EA), sublimation temperature, and melting point. No decomposition was observed when stored under an inert atmosphere at room temperature for long periods of time. However, the compounds decomposed, without clear visual signs, when exposed to air and were no longer soluble in dry hexane. Presumably, the compounds formed nonsoluble mixed aluminum hydroxides and oxides.

Purification of the crudes of $\mathbf{1 - 6}$ by vacuum sublimation was unsuccessful due to impurities that cosublimed. We suspect that these impurities decomposed during sublimation to form white solids, which were insoluble in $n$-hexane, $\mathrm{Et}_{2} \mathrm{O}$, THF, and toluene. Interestingly, the ${ }^{1} \mathrm{H}$ NMR spectra of 1-6 showed no impurities after sublimation. However, satisfactory EA was not obtained from the sublimed and filtered solid. To obtain satisfactory EA, the compounds were therefore purified by recrystallization from $\mathrm{Et}_{2} \mathrm{O} / \mathrm{MeCN}$.

The crystal structure of $\mathbf{6}$ showed the aluminum in an octahedral coordination geometry bearing three sets of the 1,3di-tert-butyltriazenide ligand (Figure 1). A large degree of

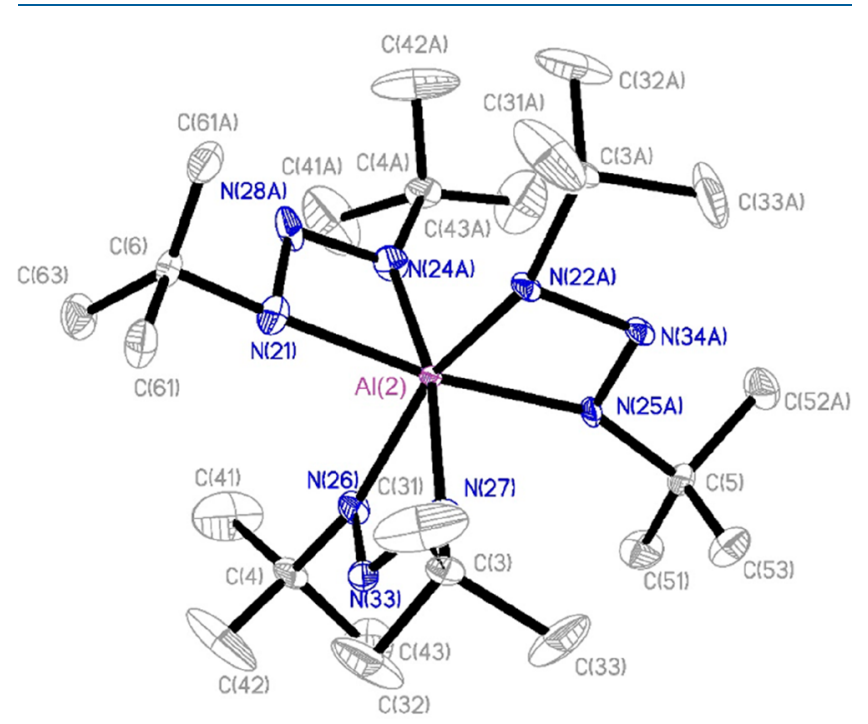

Figure 1. ORTEP drawing for one of two independent molecules in the unit cell of 6. Thermal ellipsoids are displayed at the $50 \%$ probability level, and hydrogen atoms are omitted for clarity.

disorder was observed in the diffraction data. The ligands are distorted over a multitude of positions (at least 8 individual sets of possible arrangements). The $\mathrm{Al}-\mathrm{N}$ bond length for 6 (av 1.96(5) $\AA$ ) are similar to that for $\operatorname{tris}(1,3$ diphenyltriazenide)aluminum(III) (av 1.972(5) $\AA)^{28}$ but

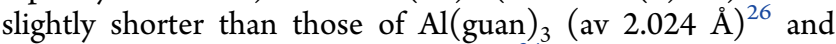
$\mathrm{Al}(\mathrm{amd})_{3}$ (av 2.0195 and $2.0261 \AA$ ). ${ }^{34}$ Thus, the triazenide ligand only has a small effect on the $\mathrm{Al}-\mathrm{N}$ bond length in comparison to $\mathrm{Al}$ (guan) $)_{3}$ and $\mathrm{Al}$ (amd) $)_{3}$. Compound 1 has an analogous structure to that of $\mathbf{6}$, but suffers from even more severe disorder and therefore no successful refinement could be completed (see the Supporting Information).

The DFT calculated geometry of $\mathbf{6}$ is consistent with its crystal structure. The highest occupied molecular orbital (HOMO) and lowest unoccupied molecular orbital (LUMO) are both localized on the ligands (Figure 2). While the HOMO is spread over all three ligands, the LUMO only covers the $\mathrm{N}_{3}$ backbone of two ligands. For the HOMO, one node is centered on the endocyclic nitrogen, while the LUMO has nodes between the endocyclic and exocyclic nitrogens. The
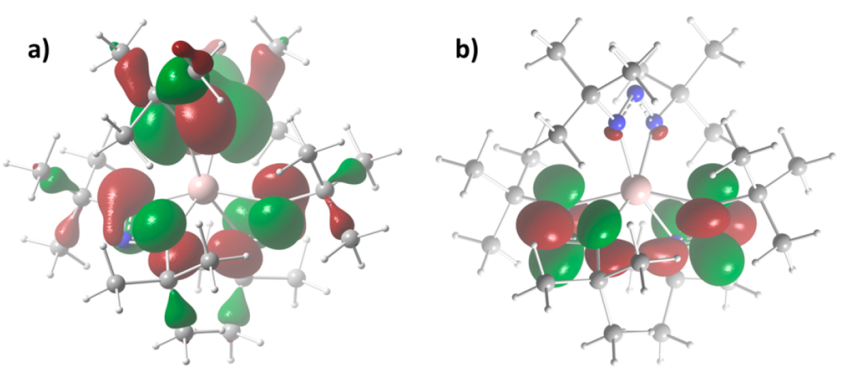

Figure 2. (a) HOMO $(-5.74 \mathrm{eV})$ and (b) LUMO $(-0.78 \mathrm{eV})$ for 6 from DFT calculations. 
natural charges of the exocyclic nitrogens $(-0.48)$ and $\mathrm{Al}$ metal center $(+1.66)$ indicate a highly polarized $\mathrm{Al}-\mathrm{N}$ bond character. The primary carbons $(-0.60)$ show negative charges, while the endocyclic nitrogens $(+0.044)$ and tertiary carbons $(+0.11)$ have slightly positive charges. Comparing the natural bond orbital charge of the $\mathrm{Al}$ center of 1 (1.61) and its formamidinate analogue (1.86) shows the greater electron donating ability of the triazenide ligand over the formamidinate (see the Supporting Information).

The ${ }^{27} \mathrm{Al}$ NMR spectra of compounds $\mathbf{1 - 6}$ each gave a broad peak at $\delta_{\mathrm{Al}}=25.1-27.5 \mathrm{ppm}$ (see the Supporting Information). These chemical shifts are consistent with previously reported hexacoordinated $\mathrm{Al}$ (III) triazenide complexes $\left(\delta_{\mathrm{Al}}=25-28 \mathrm{ppm}\right){ }^{28,29}$ Dynamic effects were observed by ${ }^{1} \mathrm{H}$ NMR for the unsymmetrical ligated compounds 2, 3, and $\mathbf{5}$ at $25^{\circ} \mathrm{C}$ (see the Supporting Information). These effects are most likely caused by isomerization hindered by the bulky ligands surrounding the small $\mathrm{Al}$ (III) center. ${ }^{35,36}$ Therefore, the complexes isomerize slowly, resulting in significant lifetimes for the signals in relation to the difference in resonance frequencies. ${ }^{37}$ Heating resolves the lifetime broadening by increasing the rate of isomerization. Mild line broadening was observed for compound 2 at $25{ }^{\circ} \mathrm{C}$ and was resolved at $35{ }^{\circ} \mathrm{C}$. Line splitting was observed for all but the $\mathrm{CH}$ signals for compounds 3 and $\mathbf{5}$. These more severe effects are caused by the presence of the bulky tert-butyl groups, which further inhibit isomerization. The line splitting was resolved at $45{ }^{\circ} \mathrm{C}$ with only line broadening remaining. Heating to $50{ }^{\circ} \mathrm{C}$ resolved the line broadening for compound 3. However, mild line broadening was still observed for $\mathbf{5}$.

2.2. Thermal Analysis of Aluminum Complexes. Compounds 1, 3, 5, and 6 volatilize quantitatively with exponential mass loss in thermogravimetric analysis (TGA) (Figure 3). Compound 2 has $4 \%$ residual mass by TGA, undergoing slight decomposition, as observed by an inflection in the derivative at approximately $200{ }^{\circ} \mathrm{C}$ (see the Supporting Information). TGA of 4 showed two distinct events of mass loss, giving 5-7\% residual mass. We speculate that 4 decomposes into volatile fragments during the mass loss

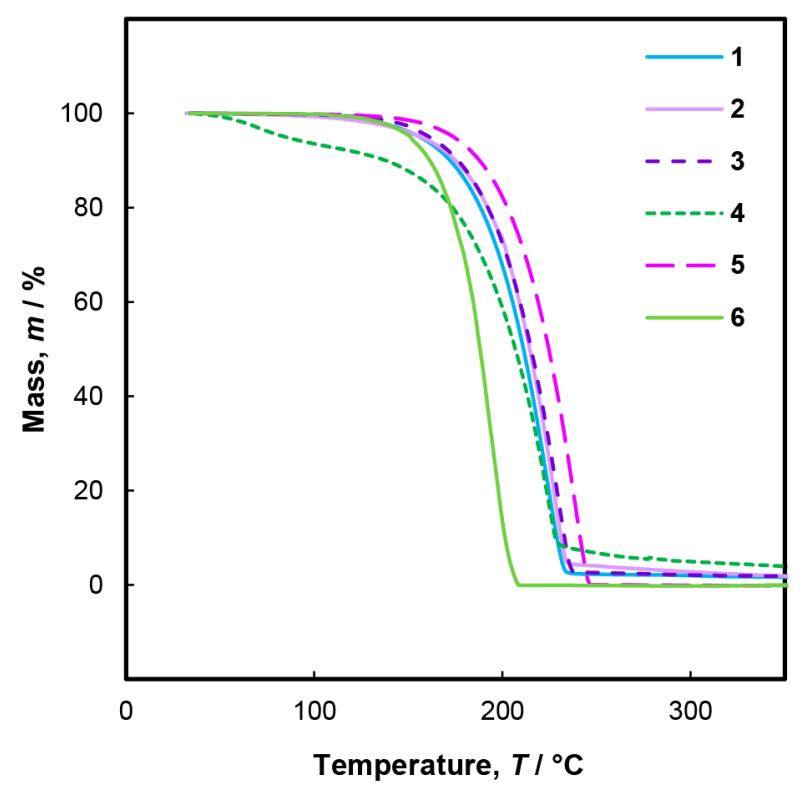

Figure 3. Thermogravimetric analysis of 1-6. events. However, we were unable to obtain a satisfactory elemental analysis for 4; therefore, the residual mass may be due to impurities. Overall, TGA shows that compounds 1-6 are sufficiently volatile for use in ALD. In fact, compounds 1-6 are far more volatile than $\mathrm{Al}(\mathrm{amd})_{3}$ and $\mathrm{Al}$ (guan), ${ }_{3},{ }^{26,27}$ which can be explained by more electron density residing on the triazenide ligand. This leads to weaker intermolecular interactions in the crystal structure of the compound, which is conditional for faster volatilization (see the Supporting Information for a comparison of charges between $\mathbf{1}$ and its amidinate analogue).

Differential scanning calorimetry (DSC) was employed to study exothermic events of 1-6. All compounds have exothermic events, most likely due to decomposition, overlapping with their onset of volatilization displayed in TGA (see the Supporting Information). The TGA and DSC results for 1-6 are summarized in Table 1 . Compounds 1 and 5 have

Table 1. Summarized TGA and DSC Results for 1-6

\begin{tabular}{lccccc}
$\begin{array}{c}\text { 1st DSC } \\
\text { exotherm } \\
\left({ }^{\circ} \mathrm{C}\right)\end{array}$ & $\begin{array}{c}\text { onset of } \\
\text { volatilization } \\
\left({ }^{\circ} \mathrm{C}\right)\end{array}$ & $\begin{array}{c}\text { 1 Torr vapor } \\
\text { pressure }\left({ }^{\circ} \mathrm{C}\right)\end{array}$ & $\begin{array}{c}\text { residual } \\
\text { mass } \\
(\%)\end{array}$ & $\begin{array}{c}\text { sublimation } \\
\text { temp }{ }^{a}\left({ }^{\circ} \mathrm{C}\right)\end{array}$ \\
\hline $\mathbf{1}$ & $150-230$ & 155 & 134 & 2 & 90 \\
$\mathbf{2}$ & $130-190$ & 153 & 138 & 4 & 90 \\
$\mathbf{3}$ & $160-300$ & 161 & 137 & 2 & 105 \\
$\mathbf{4}$ & $105-160$ & $\mathrm{~N} / \mathrm{A}$ & $\mathrm{N} / \mathrm{A}$ & 7 & 90 \\
$\mathbf{5}$ & $160-240$ & 175 & 172 & 0 & 120 \\
$\mathbf{6}$ & $230-280$ & 151 & 134 & 0 & 125
\end{tabular}

${ }^{a}$ Vacuum sublimation was undertaken at 0.5 mbar.

exothermic events starting at 150 and $160{ }^{\circ} \mathrm{C}$, respectively. Both compounds give peaks with irregular shape, indicating overlapping exothermic events occurring. Two distinct exotherms are observed for 2, 3, and 6: the first event initiates at 130,160 , and $230{ }^{\circ} \mathrm{C}$, respectively, and the second between 234 and $300{ }^{\circ} \mathrm{C}$. Compound 4 has a small exotherm starting at $\sim 100{ }^{\circ} \mathrm{C}$, followed by a larger event at $\sim 200{ }^{\circ} \mathrm{C}$. The unsymmetrical compounds 2,3 , and 5 undergo exothermic events at similar temperatures to $\mathbf{1}$. That is, greater ligand bulk does not increase thermal stability of these compounds. However, the exothermic event of $\mathbf{6}$ is at significantly higher temperatures compared to $\mathbf{1}$. Interestingly, $\mathbf{1}$ and $\mathbf{6}$ have similar calculated 1 Torr vapor pressure temperatures (Table 1).

To study the long-term thermal stability of compounds 1-6, their solids were each flamed sealed in an NMR tube and heated to $5{ }^{\circ} \mathrm{C}$ above their 1 Torr vapor pressure temperature (Table 1) for 7 days. After heat exposure, compounds 1, 2, and 5 fully dissolved in $\mathrm{C}_{6} \mathrm{D}_{6}$ while 3 and 6 had a small amount of insoluble solid. None of the compounds showed signs of decomposition by ${ }^{1} \mathrm{H}$ NMR.

A solution of 1 in $\mathrm{C}_{6} \mathrm{D}_{6}$ was heated in a flame-sealed NMR tube to various temperatures for $1 \mathrm{~h}$, followed by acquiring ${ }^{1} \mathrm{H}$ NMR spectra (Figure 4). After flame sealing but before heating the sample, the ${ }^{1} \mathrm{H}$ NMR spectrum showed newly formed, lowintensity impurity signals (red asterisk, Figure 4). Only small changes to 1 occurred when heating up to $180{ }^{\circ} \mathrm{C}$, and the solution remained colorless. Above $210^{\circ} \mathrm{C}$, the solution turned yellow, and ${ }^{1} \mathrm{H}$ NMR signals of the doublet and septet, at 1.25 and $3.88 \mathrm{ppm}$, respectively, decreased in intensity. A white precipitate formed at $225{ }^{\circ} \mathrm{C}$, and the overall ${ }^{1} \mathrm{H}$ NMR signal of 1 had decreased significantly. Traces of various decom- 


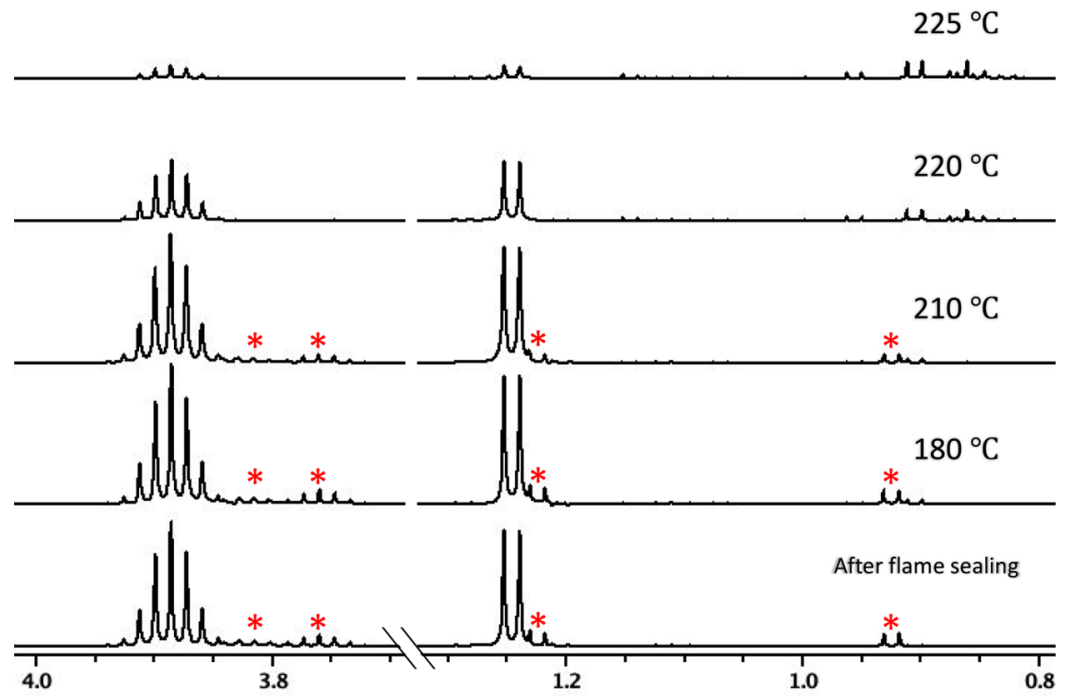

Figure 4. The ${ }^{1} \mathrm{H}$ NMR ( $500 \mathrm{MHz}, \mathrm{C}_{6} \mathrm{D}_{6}$ ) spectra from a decomposition study of 1 between $0.8-1.3$ and $3.7-4.0$ ppm separated by an axis break. For visibility, the $y$-axis is scaled up $\sim 18$ times on the left of the axis break compared to the right side. Prior to flame sealing, the compound showed no traces of impurities by ${ }^{1} \mathrm{H}$ NMR analysis. The peaks marked with an asterisk appeared after flame sealing the tube. Compound 1 was heated in $\mathrm{C}_{6} \mathrm{D}_{6}$, and all spectra were acquired at $50{ }^{\circ} \mathrm{C}$ to suppress line broadening. The decomposition of 1 accelerates after $210^{\circ} \mathrm{C}$, which is shown by the diminished quartet and doublet peaks.

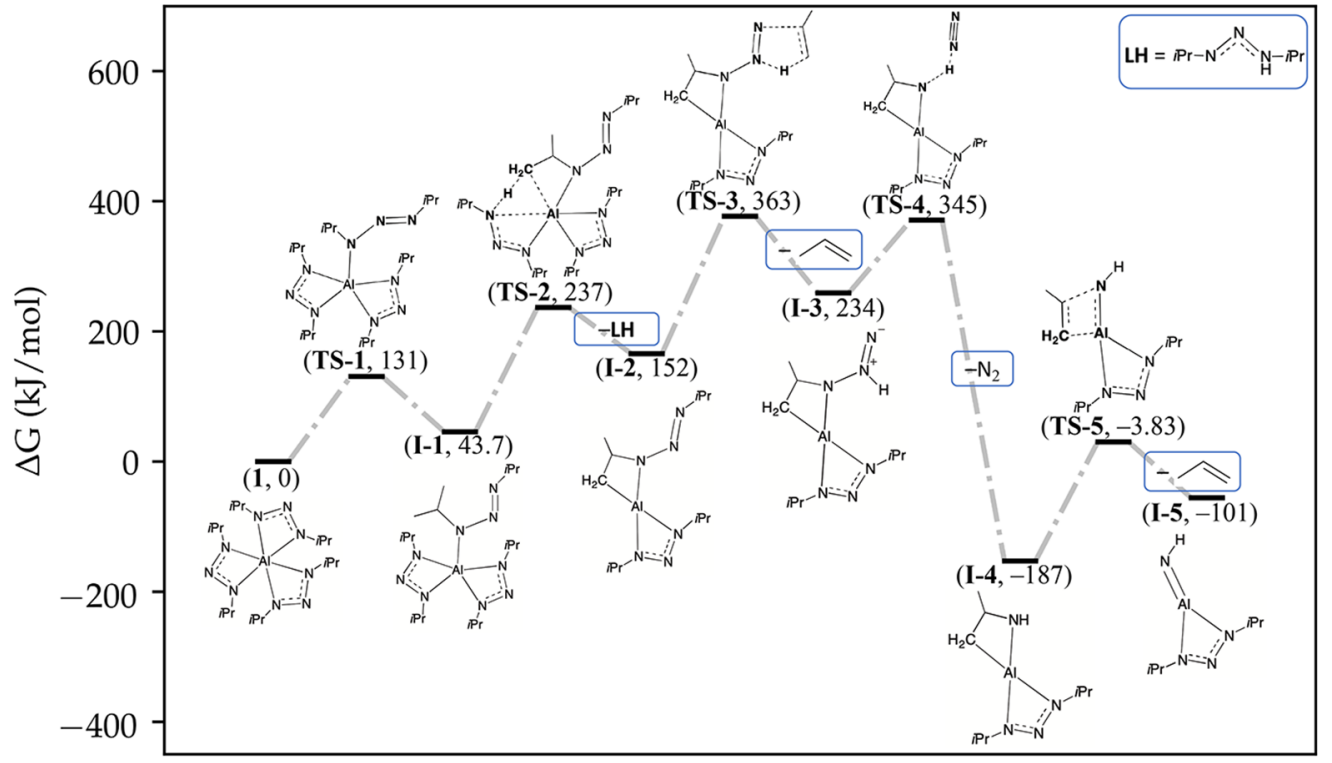

Reaction coordinates

Figure 5. Free energy profile (at $250{ }^{\circ} \mathrm{C}$ and $10 \mathrm{hPa}$ ) for the first half of the decomposition pathway. Here, 1 loses a triazene ligand (after TS-2), and one ligand decomposes into an imido ligand (TS-5). TS-3 has the largest free energy $\left(211 \mathrm{kJmol}^{-1}\right)$ for the displayed part of the decomposition pathway. The overall largest free energy barrier is found at TS-8 $\left(214 \mathrm{kJmol}^{-1}\right)$ : the analogous step to TS-3 but for the last ligand. At $250^{\circ} \mathrm{C}$ and $10 \mathrm{hPa}$, the adduct structures I-2A separate spontaneously (i.e., the process is barrierless and has a negative free energy difference) and is therefore not included.

position products appear in the ranges 3.0-2.7, 2.4-2.5, and 2.0-0.7 ppm (see the Supporting Information).

2.3. Gas-Phase Decomposition by DFT Computations. In previous work, we demonstrated high-quality thin films of indium nitride and gallium nitride by ALD, using the $\mathrm{Ga}(\text { triaz })_{3}$ and $\mathrm{In}(\text { triaz })_{3}$ as precursors, respectively. ${ }^{31,30}$ From the thermal properties of the compounds, we speculated that the depositions are activated by gas-phase decomposition of the precursor in the ALD reactor. Compounds 1-6 have similar thermal properties as $\mathrm{Ga}(\text { triaz })_{3}$ and $\operatorname{In}(\text { triaz })_{3}$ and are therefore expected to undergo a similar decomposition. DFT was used to study gas-phase thermal decomposition pathways of 1. We found a decomposition pathway relying on Brönsted-Lowry acid-base reactions between neighboring ligands. Overall, the first ligand leaves as triazene while the second decomposes into an imido ligand. Figure 5 shows the free energy profile for the release and decomposition of the first and second ligand, respectively, at $250{ }^{\circ} \mathrm{C}$ and $10 \mathrm{hPa}$. The third ligand decomposes in the same manner as the second, only with minor differences (Figure 6). The largest free energy barriers are 211 and $214 \mathrm{~kJ} \mathrm{~mol}^{-1}$, for TS-3 (Figure 5) and TS8 (Figure 6), respectively. These barriers are slightly smaller 


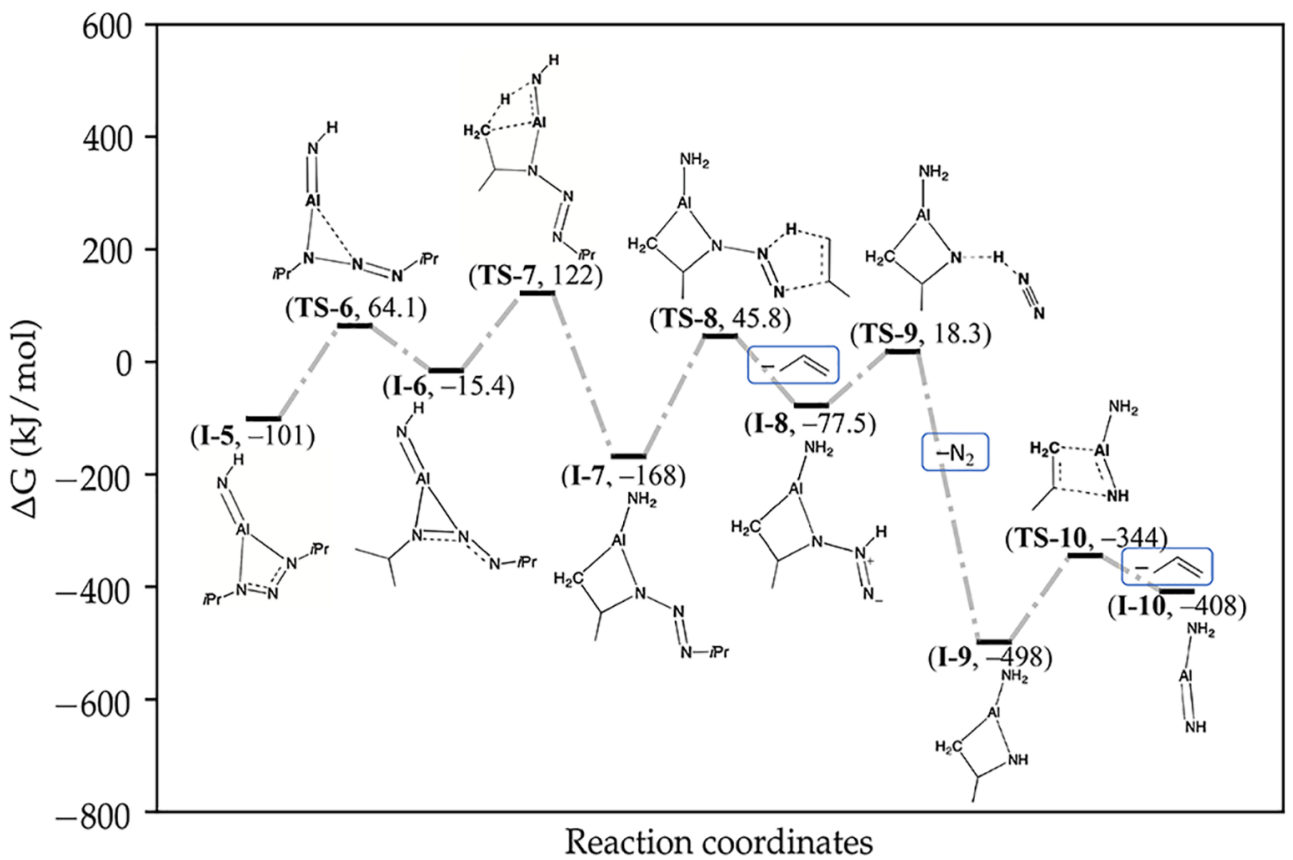

Figure 6. Free energy profile continuing from I-5. The steps that transform I-5 into I-10 are analogous to the steps that transform $\mathbf{1}$ into I-5. The reverse step through TS-7 has a significantly larger free energy barrier compared to the analogous TS-2 (290 vs $85 \mathrm{~kJ} \mathrm{~mol}^{-1}$, respectively).

for 6 (192 and $\left.197 \mathrm{~kJ} \mathrm{~mol}^{-1}\right)$. The Supporting Information contains pictures and Cartesian coordinates of all optimized geometries and their respective enthalpies and free energies.

Starting from 1, a ligand dechelates from the metal center by a $180^{\circ}$ rotation of a N-N bond (TS-1), resulting in I-1. This ligand dechelation enables the isopropyl moiety on the coordinated nitrogen to move closer to neighboring ligands and the metal center. Next, a methyl proton of the isopropyl group migrates to an exocyclic nitrogen on a neighboring ligand (TS-2). Simultaneously, a bond is formed between the deprotonated isopropyl group and the metal center. In I-2A, the deprotonated ligand regains a bidentate binding mode, now with a $\mathrm{C}, \mathrm{N}$-coordination to the metal center. Meanwhile, the protonated ligand dechelates and only has a coordination bond to the metal center. Due to the proton transfer in TS-2, the deprotonated and protonated ligand become dianionic and neutral, respectively. I-2A is an adduct structure consisting of a triazene ( $\mathrm{LH})$ coordinated to the I-2 structure.

The two steps that transform $\mathbf{1}$ into I-2A are reversible. In contrast, separating I-2A into LH and I-2 may be reversible or irreversible depending on the reaction conditions (Scheme 2). I-2A separates spontaneously under reduced pressure and elevated temperature, conditions commonly employed in ALD. Therefore, we assume that when the adduct structure separates, $\mathrm{LH}$ becomes inaccessible to I-2 and cannot facilitate the backward reaction, i.e., making the forward reaction irreversible.

I-2 has two triazenide ligands: the dianionic C,Ncoordinated ligand and an unaltered N,N-coordinated ligand. The dianionic ligand decomposes in three irreversible steps, transforming the $\mathrm{C}, \mathrm{N}$-coordinated triazenide into an imido ligand (Scheme S2). First, a methyl proton migrates from the isopropyl group on the $\beta$-nitrogen to the $\alpha$-nitrogen, with respect to the coordinated nitrogen (TS-3). This proton transfer results in a molecule of propene leaving the structure, giving I-3. Second, the proton on the $\alpha$-nitrogen migrates to the coordinated nitrogen (TS-4), releasing dinitrogen to give

Scheme 2. Separation of the Adduct Structure I-2A into a Triazene and $\mathrm{I}-2^{a}$<smiles>CCCN(N=NC(C)C)C1(N(CC)N=NC(C)C)CC(C)N1CCC</smiles>

I-2A

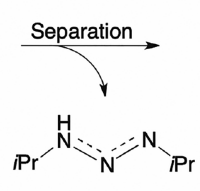

${ }^{a}$ The I-2 intermediate has one monoanionic N,N-coordinated and one dianionic $\mathrm{C}, \mathrm{N}$-coordinated triazenide ligand.

I-4. Third, passing through TS-5, the former isopropyl group, which coordinated to the metal center in TS-2, leaves as propene to give I-5.

Other than the newly formed imido ligand, I-5 has one intact triazenide ligand that decomposes in a similar fashion as the first (Figure 6). Moving from I-5 toward TS-6, the intact triazenide dechelates by rotating $180^{\circ}$ along a $\mathrm{N}-\mathrm{N}$ bond, breaking the four-membered ring with the metal center. This step is analogous to the dechelation that transform 1, via TS-1, into I-1. In contrast to I-1, however, where the ligand remained monodentate, I-6 is a less crowded structure and allows the triazenide ligand to regain a bidentate binding mode. In I-6, two adjacent nitrogen atoms of the triazenide ligand bind to the metal center, forming a three-membered ring. For the interligand proton migration (TS-7) to occur, the ligand must adopt a monodentate binding mode. When approaching TS-7 from I-6, the three-membered ring open and the ligand becomes monodentate without passing a transition state. Next, the second interligand proton transfer of the decomposition pathway occurs (TS-7). This step is similar to the first (TS-2) except that, now, the neighboring imido ligand 
Table 2. Summarized EI-MS Signals (Given in $m / z$ ) And Their Matching Intermediate Fragments from the Presented Decomposition Pathway for Compounds 1 and 6

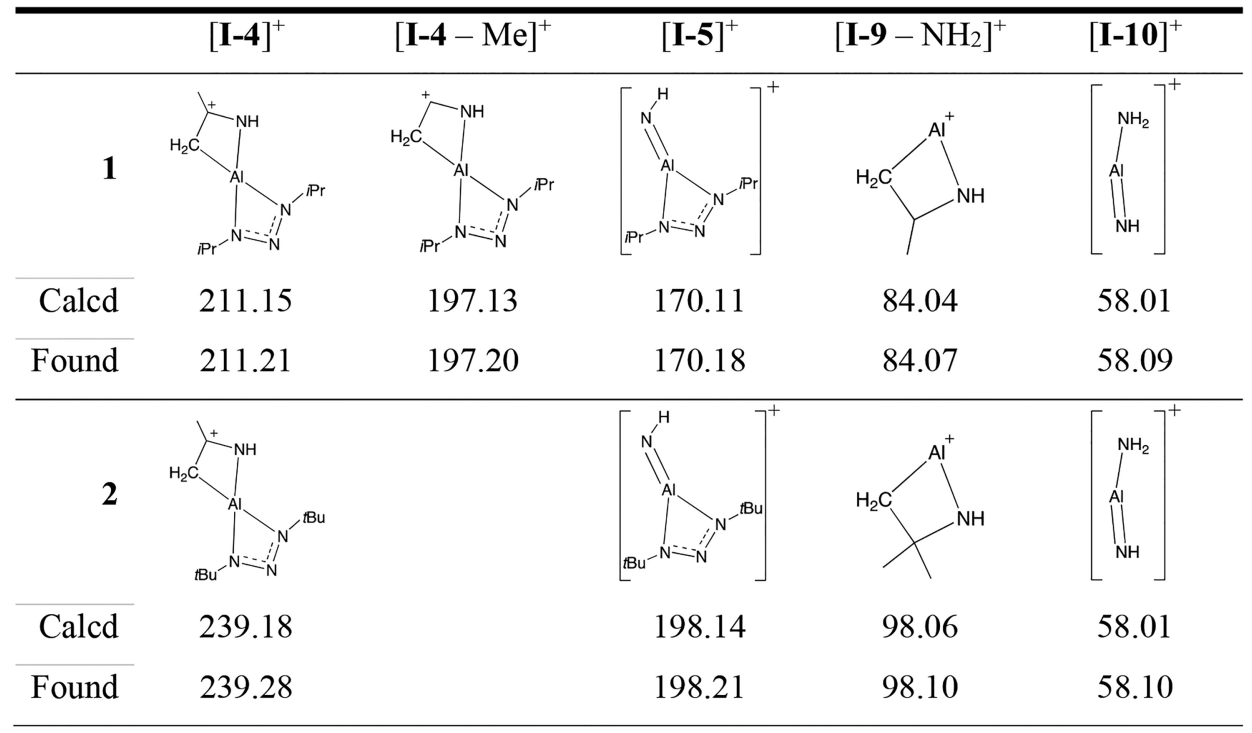

acts as the Brønsted-Lowry base instead of a neighboring triazenide ligand. Furthermore, this step has a significantly lower free energy barrier compared to TS-2 due to the imido being a much stronger base compared to the triazenide ligand. For the same reason, the free energy barrier for the reverse reaction via TS-7 is very large $\left(290 \mathrm{~kJ} \mathrm{~mol}^{-1}\right)$, essentially blocking the backward reaction. After passing TS-7, the deprotonated and protonated ligands transform into a dianionic $\mathrm{C}, \mathrm{N}$-coordinated triazenide and an amido ligand, respectively, to give $\mathbf{I}-7$.

The second dianionic triazenide decompose into an imido ligand via TS-8 to TS-10, which are analogous to TS-3 to TS5, giving the adduct structure I-10A. The adduct separates spontaneously into the final structure, I-10, and propene. A lack of viable options for I-10 to further decompose makes it thermally stable in the gas phase. However, based on the structure, I-10 is expected to be highly reactive toward surfaces. EI-MS data for $\mathbf{1}$ show four signals consistent with fragments for intermediates of the presented decomposition pathway (see the Supporting Information). Three potential fragments are identified for $\mathbf{6}$ and these fragments are structurally analogous to fragments found for 1. Furthermore, both compounds give a low intensity signal $(\sim 1 \%)$ at $m / z 58$, matching I-10. The calculated and found $\mathrm{m} / \mathrm{z}$ for all fragments are given in Table 2 .

\section{CONCLUSION}

In conclusion, six tris(1,3-dialkyltriazenide)aluminum(III) compounds have been made in good yields. The crystal structure of 6 revealed a homoleptic complex with three sets of the 1,3-di-tert-butyltriazenide ligand chelating to the $\mathrm{Al}$ (III) center. The complexes are highly volatile and, with the exception of 4, volatilize in a single step with exponential mass loss. Exponential mass loss indicated that the compounds volatilize without decomposing. However, DSC revealed exothermic events, most likely due to decomposition, overlapping with the temperature range for the mass loss event in TGA. Therefore, the compounds may undergo decomposition upon or after volatilization. Using DFT, a gas-phase decomposition pathway was found that relies on protons migrating between ligands. One ligand leaves the complex as a molecule of triazene, and the two remaining ligands transform into $\mathrm{C}, \mathrm{N}$-coordinated dianionic triazenide ligands that decompose into imido ligands. The largest free energy barrier for the pathway is $214 \mathrm{~kJ} \mathrm{~mol}^{-1}$ (at $10 \mathrm{hPa}$ and $250^{\circ} \mathrm{C}$ ) during decomposition of the second dianionic ligand (Figure 6, TS8). A slightly lower free energy barrier of $211 \mathrm{~kJ} \mathrm{~mol}^{-1}$ (at 10 $\mathrm{hPa}$ and $250^{\circ} \mathrm{C}$ ) is found for TS-3 (decomposition of the first ligand, analogous to TS-8). The final intermediate of the pathway is predicted to be highly reactive. Further studies are required to form a better understanding of how the compounds behave during the mass loss events observed in TGA. To our knowledge, compounds $\mathbf{1 - 6}$ are the first hexacoordinated $\mathrm{Al}-\mathrm{N}$ bonded compounds that are sufficiently volatile for use as $\mathrm{Al}$ precursors in vapor deposition. Based on thermal analysis and DFT calculations, we postulate that the compounds decompose into smaller and more reactive species in the gas phase, which would be highly beneficial for ALD.

\section{EXPERIMENTAL SECTION}

4.1. General Experimental Procedures. Caution! As catenated nitrogen compounds are known to be associated with explosive hazards, alkylazides and compounds 1-6 are possible explosive energetic materials. Although we have not experienced any problems in the synthesis, characterization, sublimation, heating, and handling of compounds 1-6, their energetic properties have not been fully investigated and are therefore unknown. We therefore highly recommend that all appropriate standard safety precautions for handling explosive materials (safety glasses, face shield, blast shield, leather gloves, polymer apron, and ear protection) be used at all times when working with isopropyl-, sec-butyl-, and tertbutylazide and compounds $\mathbf{1 - 6 .}$

All reactions and manipulations were carried out under a $\mathrm{N}_{2}$ atmosphere on a Schlenk line using Schlenk air-free techniques, or in a $\mathrm{N}_{2}$-filled drybox from Glovebox-Systemtechnik. All anhydrous solvents were purchased from Sigma-Aldrich and further dried with molecular sieves $4 \AA$. Isopropyllithium ( $0.7 \mathrm{M}$ in pentane), secbutyllithium (1.4 M in cyclohexane), and tert-butyllithium (1.7 M in pentane) were purchased from Sigma-Aldrich, and $\mathrm{AlCl}_{3}$ (99.985\%) was purchased from Alfa Aesar; all were used without further purification. Tert-butyl-, sec-butyl-, and isopropylazide were synthesized according to previously reported literature procedures. ${ }^{32,33}$ All 
NMR spectra were measured with Oxford Varian 300 and AS500 spectrometers at room temperature unless otherwise stated. Solvents' peaks were used as an internal standard for the ${ }^{1} \mathrm{H}$ NMR (300 and $500 \mathrm{MHz}$ ) and ${ }^{13} \mathrm{C}$ NMR (75 and $125 \mathrm{MHz}$ ) spectra. For temperature stability measurements using NMR, a $40 \mathrm{~g} \mathrm{~L}^{-1}$ solution of $\mathbf{1}$ in $\mathrm{C}_{6} \mathrm{D}_{6}$ was added to a heavy-walled NMR tube, and the tube was flame-sealed. EI-MS data for $\mathbf{1}$ and $\mathbf{6}$ were acquired using a Varian MAT spectrometer operated at $70 \mathrm{eV}$ in the electron ionization mode. Samples were filled into steel cartridges, sealed with lids, and individually fed to the spectrometer via a load-lock chamber which was pumped to ultrahigh vacuum prior to sample transfer to the main chamber. Melting points were determined for samples under $\mathrm{N}_{2}$ atmosphere, flame-sealed in capillaries, using a Stuart SMP10 melting point apparatus and are uncorrected. Elemental analysis was performed by Mikroanalytisches Laboratorium Kolbe, Germany. Purification of compounds $\mathbf{1 - 6}$ by sublimation gave unsatisfactory EA results. Satisfactory EA results were obtained by recrystallizing the sublimed compounds.

4.2. General Synthesis Procedure for Al(III) Triazenide Complexes. Alkyllithium (3 equiv) was added to a solution of alkyl azide ( 3 equiv) in $\mathrm{Et}_{2} \mathrm{O}$ at $-78{ }^{\circ} \mathrm{C}$, and the reaction mixture was stirred at this temperature for $30 \mathrm{~min}$ and then at room temperature for $1 \mathrm{~h}$. This solution was then added to a $-78{ }^{\circ} \mathrm{C}$ solution of $\mathrm{AlCl}_{3}(1$ equiv) in $\mathrm{Et}_{2} \mathrm{O}$ via cannula. The reaction mixture was stirred at this temperature for $30 \mathrm{~min}$ and then slowly warmed to room temperature and stirred for $16 \mathrm{~h}$. The reaction mixture was then concentrated under reduced pressure, and the resulting residue was suspended in $n$ hexane. Solids were filtered off through a pad of Celite and concentrated under reduced pressure to give the crude product. Purifying the crude product by sublimation resulted in unsatisfactory purity by EA. The crude product was therefore purified by recrystallization from $\mathrm{Et}_{2} \mathrm{O} / \mathrm{MeCN}$ at $-35{ }^{\circ} \mathrm{C}$ to give the desired tris(1,3-dialkyltriazenide)aluminum(III) complexes, 1-6.

Tris(1,3-diisopropyltriazenide)aluminum(III) (1). Compound 1 was synthesized according to the general procedure using isopropyl azide $(0.42 \mathrm{~g}, 4.93 \mathrm{mmol})$ in $\mathrm{Et}_{2} \mathrm{O}(25 \mathrm{~mL})$, isopropyllithium $(7.05$ $\mathrm{mL}, 4.93 \mathrm{mmol})$, and $\mathrm{AlCl}_{3}(0.22 \mathrm{~g}, 1.65 \mathrm{mmol})$ in $\mathrm{Et}_{2} \mathrm{O}(25 \mathrm{~mL})$. The solid was purified by recrystallization to give 1 as a solid $(0.39 \mathrm{~g}$, $58 \%)$.

1: Colorless solid, mp $255-257{ }^{\circ} \mathrm{C}$. Sublimation: $90{ }^{\circ} \mathrm{C}$ (at 0.5 mbar). ${ }^{1} \mathrm{H}$ NMR $\left(300 \mathrm{MHz}, \mathrm{C}_{6} \mathrm{D}_{6}\right): \delta 1.25\left(\mathrm{~d}, J=6.7 \mathrm{~Hz}, 36 \mathrm{H}, \mathrm{CH}_{3}\right)$, 3.88 (sept, $J=6.7 \mathrm{~Hz}, 6 \mathrm{H}, \mathrm{CH}) .{ }^{13} \mathrm{C}\left\{{ }^{1} \mathrm{H}\right\}$ NMR $\left(75 \mathrm{MHz}, \mathrm{C}_{6} \mathrm{D}_{6}\right): \delta$ $23.4\left(\mathrm{~s}, \mathrm{CH}_{3}\right), 52.6(\mathrm{~s}, \mathrm{CH}) .{ }^{27} \mathrm{Al} \mathrm{NMR}\left(78 \mathrm{MHz}, \mathrm{C}_{6} \mathrm{D}_{6}\right): \delta 25.1(\mathrm{br}$ s). EI-MS (LR): 43.1 (60\%), 84.1 (4.3\%), $156.2(15 \%), 170.3(1.4 \%)$, 197.2 (9.3\%), 211.2 (19\%), 283.3 (30\%). Anal. Calcd for $\mathrm{C}_{18} \mathrm{H}_{42} \mathrm{AlN}_{9}$ : C, $52.53 \%$; H, $10.29 \%$; N, 30.63\%. Found: C, $51.70 \%$; H, $10.31 \%$; N, 30.04\%.

Tris(1-isopropyl-3-sec-butyltriazenide)aluminum(III) (2). Compound 2 was synthesized according to the general procedure using sec-butyl azide $(0.59 \mathrm{~g}, 5.95 \mathrm{mmol})$ in $\mathrm{Et}_{2} \mathrm{O}(30 \mathrm{~mL})$, isopropyllithium $(8.50 \mathrm{~mL}, 5.95 \mathrm{mmol})$, and $\mathrm{AlCl}_{3}(0.26 \mathrm{~g}, 1.98 \mathrm{mmol})$ in $\mathrm{Et}_{2} \mathrm{O}(30$ $\mathrm{mL}$ ). The solid was purified by recrystallization to give 2 as a solid (0.55 g, 61\%).

2: Colorless solid, mp $187-192{ }^{\circ} \mathrm{C}$. Sublimation: $90{ }^{\circ} \mathrm{C}$ (at 0.5 mbar). ${ }^{1} \mathrm{H}$ NMR $\left(300 \mathrm{MHz}, \mathrm{C}_{6} \mathrm{D}_{6}\right): \delta 0.92\left(\mathrm{t}, J=7.5 \mathrm{~Hz}, 9 \mathrm{H}, \mathrm{CH}_{3}\right)$, $1.26\left(\mathrm{~d}, J=6.6 \mathrm{~Hz}, 18 \mathrm{H}, \mathrm{CH}_{3}\right), 1.26\left(\mathrm{~d}, J=6.6 \mathrm{~Hz}, 9 \mathrm{H}, \mathrm{CH}_{3}\right), 1.42-$ $1.60\left(\mathrm{~m}, 3 \mathrm{H}, \mathrm{CH}_{2}\right), 1.71-1.88\left(\mathrm{~m}, 3 \mathrm{H}, \mathrm{CH}_{2}\right), 3.63$ (sext, $J=6.6 \mathrm{~Hz}$, $3 \mathrm{H}, \mathrm{CH}), 3.87$ (sept, $J=6.6 \mathrm{~Hz}, 3 \mathrm{H}, \mathrm{CH}) .{ }^{13} \mathrm{C}\left\{{ }^{1} \mathrm{H}\right\} \mathrm{NMR}(75 \mathrm{MHz}$, $\left.\mathrm{C}_{6} \mathrm{D}_{6}\right): \delta 11.3\left(\mathrm{~s}, \mathrm{CH}_{3}\right), 20.2\left(\right.$ br s, $\left.\mathrm{CH}_{3}\right), 23.4\left(\mathrm{~s}, \mathrm{CH}_{3}\right), 30.7(\mathrm{~s}$, $\left.\mathrm{CH}_{2}\right), 52.4(\mathrm{~s}, \mathrm{CH}), 58.7(\mathrm{~s}, \mathrm{CH}) .{ }^{27} \mathrm{Al} \mathrm{NMR}\left(78 \mathrm{MHz}, \mathrm{C}_{6} \mathrm{D}_{6}\right): \delta 26.0$ (br s). Anal. Calcd for $\mathrm{C}_{21} \mathrm{H}_{48} \mathrm{AlN}_{9}$ : C, $55.60 \% ; \mathrm{H}, 10.67 \%$; , $27.79 \%$. Found: C, $53.92 \%$; H, $10.46 \%$; N, $26.42 \%$.

Tris(1-isopropyl-3-tert-butyltriazenide)aluminum(III) (3). Compound 3 was synthesized according to the general procedure using tert-butyl azide $(0.38 \mathrm{~g}, 3.83 \mathrm{mmol})$ in $\mathrm{Et}_{2} \mathrm{O}(20 \mathrm{~mL})$, isopropyllithium $(5.48 \mathrm{~mL}, 3.83 \mathrm{mmol})$, and $\mathrm{AlCl}_{3}(0.17 \mathrm{~g}, 1.28$ $\mathrm{mmol})$ in $\mathrm{Et}_{2} \mathrm{O}(20 \mathrm{~mL})$. The solid was purified by recrystallization to give 3 as a solid $(0.42 \mathrm{~g}, 72 \%)$.

3: Colorless crystals, $\mathrm{mp}>300{ }^{\circ} \mathrm{C}$. Sublimation: $105{ }^{\circ} \mathrm{C}$ (at 0.5 mbar). ${ }^{1} \mathrm{H}$ NMR $\left(300 \mathrm{MHz}, \mathrm{C}_{6} \mathrm{D}_{6}, 50{ }^{\circ} \mathrm{C}\right): \delta 1.26(\mathrm{~d}, J=6.5 \mathrm{~Hz}$,
$18 \mathrm{H}, \mathrm{CH}_{3}$ ), 1.34 (s, 27H, $\mathrm{CH}_{3}$ ), 3.82 (sept, $J=6.6 \mathrm{~Hz}, 3 \mathrm{H}, \mathrm{CH}$ ). ${ }^{13} \mathrm{C}\left\{{ }^{1} \mathrm{H}\right\}$ NMR $\left(75 \mathrm{MHz}, \mathrm{C}_{6} \mathrm{D}_{6}, 50{ }^{\circ} \mathrm{C}\right): \delta 23.4\left(\mathrm{br} \mathrm{s}, \mathrm{CH}_{3}\right), 30.7(\mathrm{~s}$, $\left.\mathrm{CH}_{3}\right), 52.1(\mathrm{~s}, \mathrm{CH}), 56.4\left(\mathrm{~s}, \mathrm{C}_{\mathrm{q}}\right) .{ }^{27} \mathrm{Al} \mathrm{NMR}\left(78 \mathrm{MHz}, \mathrm{C}_{6} \mathrm{D}_{6}\right): \delta 25.5$ (br s). Anal. Calcd for $\mathrm{C}_{21} \mathrm{H}_{48} \mathrm{AlN}_{9}$ : C, $55.60 \% ; \mathrm{H}, 10.67 \% ; \mathrm{N}$, $27.79 \%$. Found: C, $55.07 \%$; H, $10.71 \%$; N, $27.54 \%$.

Tris(1,3-di-sec-butyltriazenide)aluminum(III) (4). Compound 4 was synthesized according to the general procedure using sec-butyl azide $(0.29 \mathrm{~g}, 2.93 \mathrm{mmol})$ in $\mathrm{Et}_{2} \mathrm{O}(20 \mathrm{~mL})$, sec-butyllithium $(2.09$ $\mathrm{mL}, 2.93 \mathrm{mmol}$ ), and $\mathrm{AlCl}_{3}(0.13 \mathrm{~g}, 0.98 \mathrm{mmol})$ in $\mathrm{Et}_{2} \mathrm{O}(20 \mathrm{~mL})$. The solid was purified by sublimation at $90^{\circ} \mathrm{C}$ to give 4 as a semisolid (0.21 g, 43\%).

4: Colorless semi-solid. Sublimation: $90{ }^{\circ} \mathrm{C}$ (at $0.5 \mathrm{mbar}$ ). ${ }^{1} \mathrm{H}$ NMR $\left(300 \mathrm{MHz}, \mathrm{C}_{6} \mathrm{D}_{6}, 50{ }^{\circ} \mathrm{C}\right): \delta 0.93\left(\mathrm{t}, J=7.5 \mathrm{~Hz}, 18 \mathrm{H}, \mathrm{CH}_{3}\right)$, $1.28\left(\mathrm{~d}, J=6.0 \mathrm{~Hz}, 18 \mathrm{H}, \mathrm{CH}_{3}\right), 1.42-1.63\left(\mathrm{~m}, 6 \mathrm{H}, \mathrm{CH}_{2}\right), 1.75-1.88$ $\left(\mathrm{m}, 6 \mathrm{H}, \mathrm{CH}_{2}\right), 3.62$ (sext, $\left.J=6.6 \mathrm{~Hz}, 6 \mathrm{H}, \mathrm{CH}\right) .{ }^{13} \mathrm{C}\left\{{ }^{1} \mathrm{H}\right\}$ NMR $(75$ $\left.\mathrm{MHz}, \mathrm{C}_{6} \mathrm{D}_{6}, 50{ }^{\circ} \mathrm{C}\right): \delta 11.3\left(\mathrm{~s}, \mathrm{CH}_{3}\right), 20.2\left(\mathrm{~s}, \mathrm{CH}_{3}\right), 30.7\left(\mathrm{~s}, \mathrm{CH}_{2}\right)$, $58.6(\mathrm{~s}, \mathrm{CH}) .{ }^{27} \mathrm{Al} \mathrm{NMR}\left(78 \mathrm{MHz}, \mathrm{C}_{6} \mathrm{D}_{6}, 50{ }^{\circ} \mathrm{C}\right): \delta 27.5$ (br s). A satisfactory elemental analysis could not be obtained for compound 4 .

Tris(1-sec-butyl-3-tert-butyltriazenide)aluminum(III) (5). Compound 5 was synthesized according to the general procedure using tert-butyl azide $(0.34 \mathrm{~g}, 3.43 \mathrm{mmol})$ in $\mathrm{Et}_{2} \mathrm{O}(20 \mathrm{~mL})$, sec-butyllithium $(2.45 \mathrm{~mL}, 3.43 \mathrm{mmol})$, and $\mathrm{AlCl}_{3}(0.15 \mathrm{~g}, 1.14 \mathrm{mmol})$ in $\mathrm{Et}_{2} \mathrm{O}(20$ $\mathrm{mL})$. The solid was purified by recrystallization to give 5 as a solid (0.43 g, 75\%).

5: Colorless crystals, $\mathrm{mp}>300{ }^{\circ} \mathrm{C}$. Sublimation: $120{ }^{\circ} \mathrm{C}$ (at 0.5 mbar). ${ }^{1} \mathrm{H}$ NMR $\left(300 \mathrm{MHz}, \mathrm{C}_{6} \mathrm{D}_{6}, 50{ }^{\circ} \mathrm{C}\right): \delta 0.92(\mathrm{t}, J=7.4 \mathrm{~Hz}, 9 \mathrm{H}$, $\left.\mathrm{CH}_{3}\right), 1.27\left(\mathrm{~d}, \mathrm{~J}=6.6 \mathrm{~Hz}, 9 \mathrm{H}, \mathrm{CH}_{3}\right), 1.35\left(\mathrm{~s}, 27 \mathrm{H}, \mathrm{CH}_{3}\right), 1.40-1.62$ $\left(\mathrm{m}, 3 \mathrm{H}, \mathrm{CH}_{2}\right), 1.75-1.94\left(\mathrm{~m}, 3 \mathrm{H}, \mathrm{CH}_{2}\right), 3.51-3.66(\mathrm{~m}, 3 \mathrm{H}, \mathrm{CH})$. ${ }^{13} \mathrm{C}\left\{{ }^{1} \mathrm{H}\right\}$ NMR $\left(755 \mathrm{MHz}, \mathrm{C}_{6} \mathrm{D}_{6}, 50{ }^{\circ} \mathrm{C}\right): \delta 10.4-12.1\left(\mathrm{~m}, \mathrm{CH}_{3}\right)$, 17.9-19.7 (m, $\left.\mathrm{CH}_{3}\right), 30.5-30.9\left(\mathrm{~m}, \mathrm{CH}_{3}\right), 31.0\left(\mathrm{~s}, \mathrm{CH}_{2}\right), 56.4\left(\mathrm{C}_{\mathrm{q}}\right)$, 57.5-58.6 (m, CH). ${ }^{27} \mathrm{Al} \mathrm{NMR}\left(78 \mathrm{MHz}, \mathrm{C}_{6} \mathrm{D}_{6}\right): \delta 26.0(\mathrm{br} \mathrm{s})$. Anal. Calcd for $\mathrm{C}_{24} \mathrm{H}_{54} \mathrm{AlN}_{9}$ : C, $58.15 \%$; $\mathrm{H}, 10.98 \%$; N, $25.43 \%$. Found: C, $55.92 \%$; H, $10.66 \%$; N, $24.42 \%$.

Tris(1,3-di-tert-butyltriazenide)aluminum(III) (6). Compound 6 was synthesized according to the general procedure using tert-butyl azide $(0.45 \mathrm{~g}, 4.54 \mathrm{mmol})$ in $\mathrm{Et}_{2} \mathrm{O}(25 \mathrm{~mL})$, tert-butyllithium $(2.67$ $\mathrm{mL}, 4.54 \mathrm{mmol})$, and $\mathrm{AlCl}_{3}(0.20 \mathrm{~g}, 1.51 \mathrm{mmol})$ in $\mathrm{Et}_{2} \mathrm{O}(25 \mathrm{~mL})$. The solid was purified by recrystallization to give 6 as a solid $(0.59 \mathrm{~g}$, $78 \%)$.

6: Colorless crystals, $\mathrm{mp}>300{ }^{\circ} \mathrm{C}$. Sublimation: $125{ }^{\circ} \mathrm{C}$ (at 0.5 mbar). ${ }^{1} \mathrm{H}$ NMR $\left(300 \mathrm{MHz}, \mathrm{C}_{6} \mathrm{D}_{6}\right): \delta 1.38\left(\mathrm{~s}, 54 \mathrm{H}, \mathrm{CH}_{3}\right) .{ }^{13} \mathrm{C}\left\{{ }^{1} \mathrm{H}\right\}$ NMR $\left(75 \mathrm{MHz}, \mathrm{C}_{6} \mathrm{D}_{6}\right): \delta 31.3\left(\mathrm{~s}, \mathrm{CH}_{3}\right), 57.3\left(\mathrm{~s}, \mathrm{C}_{\mathrm{q}}\right) .{ }^{27} \mathrm{Al}$ NMR $(78$ $\mathrm{MHz}, \mathrm{C}_{6} \mathrm{D}_{6}$ ): $\delta 23.7$ (br s). EI-MS (LR): 41.1 (3.7\%), 57.1 (19\%), 98.1 (1.1\%), 198.2 (9.9\%), 239.3 (2.2\%), 339.4 (100\%), 495.5 (0.51\%). Anal. Calcd for $\mathrm{C}_{24} \mathrm{H}_{54} \mathrm{AlN}_{9}$ : C, 58.15\%; H, $10.98 \%$; , 25.43\%. Found: C, $58.21 \%$; H, $10.96 \%$; N, $25.41 \%$.

4.3. X-ray Crystallographic Analysis. Colorless single crystals for 6 were obtained by recrystallization from $n$-hexanes at $-35{ }^{\circ} \mathrm{C}$. The single crystals were used for X-ray diffraction data collection on a Bruker D8 SMART Apex-II diffractometer, using graphite-monochromated Mo $\mathrm{K} \alpha$ radiation $(\lambda=0.71073 \AA)$ at $153 \mathrm{~K}$. All data were collected in hemisphere with over $95 \%$ completeness to $2 \theta<50.05^{\circ}$. The structure is monoclinic, centrosymmetric, space group $C 2 / m, a=$ 28.940(5), $b=16.958(3), c=9.8864(17) \AA, \beta=94.118(2)^{\circ}$. In spite of data collection at low temperature, the data produce an electron density map that is rather "flat", which is a result of very heavy disorder, rendering an almost amorphous structure. The structure was solved by direct methods. Coordinates of metal atoms were determined from the initial solutions, and from the $\mathrm{N}$ and $\mathrm{C}$ methods, located in subsequent differential Fourier syntheses. The solution does not contain much residual electron density, but it stays for a multitude of additional possible positions of light atoms. All nonhydrogen atoms were refined, first in isotropic and then in anisotropic approximation, using Bruker SHELXTL software. Additional crystal data treatment details are available from the Cambridge Crystallographic Data Centre, deposition no. CCDC 2046808.

The data collection on crystals of 1 was carried out under same conditions as for $\mathbf{6}$. An even less featured electron density map was obtained from the reflections provided by an analogous structure, monoclinic centrosymmetric, space group $C 2 / m, a=26.639(25), b=$ 
15.817(15), $c=9.184(9) \AA, \beta=95.069(14)^{\circ}$. A model analogous to that for $\mathbf{6}$ was obtained but could not be refined successfully because of poor data quality. The details for the model obtained for the structure of 1 are available in the Supporting Information.

4.4. Thermogravimetric Analysis. Volatilization and vapor pressure curves were collected using a TA Instruments thermogravimetric analysis Q500 tool operating inside a $\mathrm{N}_{2}$-filled glovebox. The ramp experiment of compounds $\mathbf{1 - 6}$ was undertaken in tared platinum pans loaded with $\sim 5-10 \mathrm{mg}$ for low mass volatilization experiments. The furnace was heated at a rate of $10^{\circ} \mathrm{C} \mathrm{min}^{-1}$ to 500 ${ }^{\circ} \mathrm{C}$ with a maintained $\mathrm{N}_{2}$ flow rate of $60 \mathrm{sccm}$. The Langmuir vapor pressure equations for compounds 1-4 and 6 were derived from TGA mass-loss derivative data of the ramp experiments according to a previously reported method ${ }^{38}$ employing bis(2,2,6,6-tetramethyl-3,5heptanedionato) copper(II) as a calibrant. ${ }^{39}$

4.5. Differential Scanning Calorimetry Analysis. DSC measurements were performed using a TA Instruments DSC Q10 tool. For each compound, 1-6, $0.2-0.5 \mathrm{mg}$ of the compound was sealed in a platinum pan in a $\mathrm{N}_{2}$-filled glovebox. All experiments were performed at a heating rate of $10{ }^{\circ} \mathrm{C} \mathrm{min}^{-1}$ between 25 and $400{ }^{\circ} \mathrm{C}$. Exothermic and endothermic events are indicated by positive and negative heat flow, respectively.

4.6. Quantum-Chemical Computations. All quantum-chemical computations were performed using Gaussian 16 software. $^{40}$ Structural optimization and harmonic normal mode vibrational calculations were performed using the hybrid DFT method B $3 L Y P^{41,42}$ together with Grimme's version 3 dispersion correction ${ }^{43}$ and def2 TZVP ${ }^{44,45}$ basis set. The decomposition pathway was investigated by searching for possible stable structures as well as finding transition states connecting these structures. Minima were confirmed to have no imaginary frequencies, while transition states were verified to have one imaginary frequency, lying along the reaction path.

\section{ASSOCIATED CONTENT}

\section{SI Supporting Information}

The Supporting Information is available free of charge at https://pubs.acs.org/doi/10.1021/acs.inorgchem.0c03496.

Characterization of the compounds and computational calculation details (PDF)

Compound 1 (CIF)

Compound 6 ( CIF)

\section{Accession Codes}

CCDC 2046808 contains the supplementary crystallographic data for this paper. These data can be obtained free of charge via www.ccdc.cam.ac.uk/data_request/cif, or by emailing data_request@ccdc.cam.ac.uk, or by contacting The Cambridge Crystallographic Data Centre, 12 Union Road, Cambridge CB2 1EZ, UK; fax: +44 1223336033.

\section{AUTHOR INFORMATION}

\section{Corresponding Author}

Nathan J. O'Brien - Department of Physics, Chemistry and Biology, Linköping University, SE-581 83 Linköping,

Sweden; 이이.org/0000-0003-3633-9674;

Email: nathan.o.brien@liu.se

\section{Authors}

Rouzbeh Samii - Department of Physics, Chemistry and Biology, Linköping University, SE-581 83 Linköping, Sweden; 이이.orid.org/0000-0001-9380-4072

David Zanders - Faculty of Chemistry and Biochemistry, Ruhr University Bochum, 44801 Bochum, Germany; Department of Chemistry, Carleton University, Ottawa, Ontario K1S5B6, Canada
Sydney C. Buttera - Department of Chemistry, Carleton University, Ottawa, Ontario K1S5B6, Canada

Vadim Kessler - Department of Molecular Sciences, Swedish University of Agricultural Sciences, 75007 Uppsala, Sweden

Lars Ojamäe - Department of Physics, Chemistry and Biology, Linköping University, SE-581 83 Linköping, Sweden; (1) orcid.org/0000-0002-5341-2637

Henrik Pedersen - Department of Physics, Chemistry and Biology, Linköping University, SE-581 83 Linköping, Sweden; 이이이.org/0000-0002-7171-5383

Complete contact information is available at: https://pubs.acs.org/10.1021/acs.inorgchem.0c03496

\section{Notes}

The authors declare no competing financial interest.

\section{ACKNOWLEDGMENTS}

The authors acknowledge Seán Barry for access to TGA and DSC instruments. This project was funded by the Swedish foundation for Strategic Research through the project "Timeresolved low temperature CVD for III-nitrides" (SSF-RMA 150018) and by the Knut and Alice Wallenberg foundation through the project "Bridging the $\mathrm{THz}$ gap" (KAW 2013.0049). L.O. acknowledges financial support from the Swedish Government Strategic Research Area in Materials Science on Functional Materials at Linköping University (Faculty Grant SFO Mat LiU 2009 00971). Supercomputing resources were provided by the Swedish National Infrastructure for Computing (SNIC) and the Swedish National Supercomputer Centre (NSC).

\section{REFERENCES}

(1) Taniyasu, Y.; Kasu, M.; Makimoto, T. An Aluminium Nitride Light-Emitting Diode with a Wavelength of 210 Nanometres. Nature 2006, 441, 325-328.

(2) Li, J.; Nam, K. B.; Nakarmi, M. L.; Lin, J. Y.; Jiang, H. X.; Carrier, P.; Wei, S.-H. Band Structure and Fundamental Optical Transitions in Wurtzite AlN. Appl. Phys. Lett. 2003, 83, 5163-5165.

(3) George, S. M. Atomic Layer Deposition: An Overview. Chem. Rev. 2010, 110, 111-131.

(4) Koponen, S. E.; Gordon, P. G.; Barry, S. T. Principles of Precursor Design for Vapour Deposition Methods. Polyhedron 2016, $108,59-66$.

(5) Van Bui, H.; Nguyen, M. D.; Wiggers, F. B.; Aarnink, A. A. I.; De Jong, M. P.; Kovalgin, A. Y. Self-Limiting Growth and Thickness- And Temperature- Dependence of Optical Constants of ALD AlN Thin Films. ECS J. Solid State Sci. Technol. 2014, 3, P101-P106.

(6) Riihelä, D.; Ritala, M.; Matero, R.; Leskelä, M.; Jokinen, J.; Haussalo, P. Low Temperature Deposition of AlN Films by an Alternate Supply of Trimethyl Aluminum and Ammonia. Chem. Vap. Deposition 1996, 2, 277-283.

(7) Liu, X.; Ramanathan, S.; Lee, E.; Seidel, T. E. Atomic Layer Deposition of Aluminum Nitride Thin Films from Trimethyl Aluminum (TMA) and Ammonia. MRS Online Proceedings Library 2003, 811, 158-153.

(8) Jung, Y. C.; Hwang, S. M.; Le, D. N.; Kondusamy, A. L. N.; Mohan, J.; Kim, S. W.; Kim, J. H.; Lucero, A. T.; Ravichandran, A.; Kim, H. S.; Kim, S. J.; Choi, R.; Ahn, J.; Alvarez, D.; Spiegelman, J.; Kim, J. Low Temperature Thermal Atomic Layer Deposition of Aluminum Nitride Using Hydrazine as the Nitrogen Source. Materials 2020, 13, 3387.

(9) Dendooven, J.; Deduytsche, D.; Musschoot, J.; Vanmeirhaeghe, R. L.; Detavernier, C. Conformality of $\mathrm{Al} 2 \mathrm{O} 3$ and AlN Deposited by Plasma-Enhanced Atomic Layer Deposition. J. Electrochem. Soc. 2010, 157, G111. 
(10) Ozgit, C.; Donmez, I.; Alevli, M.; Biyikli, N. Self-Limiting LowTemperature Growth of Crystalline AlN Thin Films by PlasmaEnhanced Atomic Layer Deposition. Thin Solid Films 2012, 520, 2750-2755.

(11) Ozgit-Akgun, C.; Goldenberg, E.; Okyay, A. K.; Biyikil, N. Hollow Cathode Plasma-Assisted Atomic Layer Deposition of Crystalline AlN, GaN and AlxGal-XN Thin Films at Low Temperatures. J. Mater. Chem. C 2014, 2, 2123-2136.

(12) Bosund, M.; Sajavaara, T.; Laitinen, M.; Huhtio, T.; Putkonen, M.; Airaksinen, V. M.; Lipsanen, H. Properties of AlN Grown by Plasma Enhanced Atomic Layer Deposition. Appl. Surf. Sci. 2011, 257, $7827-7830$.

(13) Nepal, N.; Qadri, S. B.; Hite, J. K.; Mahadik, N. A.; Mastro, M. A.; Eddy, C. R. Epitaxial Growth of $\{$ AlN $\}$ Films via Plasma-Assisted Atomic Layer Epitaxy. Appl. Phys. Lett. 2013, 103, 82110.

(14) Waggoner, K. M.; Olmstead, M. M.; Power, P. P. Structural and Spectroscopic Characterization of the Compounds $[\mathrm{Al}(\mathrm{NMe} 2) 3] 2$, $[\mathrm{Ga}(\mathrm{NMe} 2) 3] 2,[(\mathrm{Me} 2 \mathrm{~N}) 2 \mathrm{Al}\{\mu$-N $(\mathrm{H}) 1$-Ad $\}] 2$ (1-Ad = 1-Adamantanyl $)$ and $[\{\mathrm{Me}(\mu-\mathrm{NPh} 2) \mathrm{Al}\} 2 \mathrm{NPh}(\mu-\mathrm{C} 6 \mathrm{H} 4)]$. Polyhedron 1990, 9 , $257-263$.

(15) Wade, C. R.; Silvernail, C.; Banerjee, C.; Soulet, A.; McAndrew, J.; Belot, J. A. Tris(Dialkylamino)Aluminums: Syntheses, Characterization, Volatility Comparison and Atomic Layer Deposition of Alumina Thin Films. Mater. Lett. 2007, 61, 5079-5082.

(16) Liu, G.; Deguns, E.; Lecordier, L.; Sundaram, G.; Becker, J. Atomic Layer Deposition of AlN with Tris(Dimethylamido) Aluminum and NH. ECS Trans. 2011, 41, 219-225.

(17) Kim, K. H.; Gordon, R. G.; Ritenour, A.; Antoniadis, D. A. Atomic Layer Deposition of Insulating Nitride Interfacial Layers for Germanium Metal Oxide Semiconductor Field Effect Transistors with High- $\kappa$ Oxide/Tungsten Nitride Gate Stacks. Appl. Phys. Lett. 2007, 90, 212104

(18) Abdulagatov, A. I.; Ramazanov, S. M.; Dallaev, R. S.; Murliev, E. K.; Palchaev, D. K.; Rabadanov, M. K.; Abdulagatov, I. M. Atomic Layer Deposition of Aluminium Nitride Using Tris(Diethylamido) Aluminum and Hydrazine or Ammonia. Russ. Microelectron. 2018, 47, $118-130$.

(19) Abdulagatov, A. I.; Amashaev, R. R.; Ashurbekova, K. N.; Ashurbekova, K. N.; Rabadanov, M. K.; Abdulagatov, I. M. Atomic Layer Deposition of Aluminum Nitride and Oxynitride on Silicon Using Tris(Dimethylamido)Aluminum, Ammonia, and Water. Russ. J. Gen. Chem. 2018, 88, 1699-1706.

(20) Gordon, R. G. Atomic Layer Deposition for Semiconductors. In Atomic Layer Deposition for Semiconductors; Hwang, C. S., Yoo, C. Y., Eds.; Springer US: New York, 2014; pp 15-46.

(21) Kim, S. B.; Jayaraman, A.; Chua, D.; Davis, L. M.; Zheng, S. L.; Zhao, X.; Lee, S.; Gordon, R. G. Obtaining a Low and Wide Atomic Layer Deposition Window $\left(150-275^{\circ} \mathrm{C}\right)$ for In2O3 Films Using an InIII Amidinate and H2O. Chem. - Eur. J. 2018, 24, 9525-9529.

(22) Rouf, P.; O’Brien, N. J.; Rönnby, K.; Samii, R.; Ivanov, I. G.; Ojamaë, L.; Pedersen, H. The Endocyclic Carbon Substituent of Guanidinate and Amidinate Precursors Controlling Atomic Layer Deposition of InN Films. J. Phys. Chem. C 2019, 123, 25691-25700.

(23) Gebhard, M.; Hellwig, M.; Parala, H.; Xu, K.; Winter, M.; Devi, A. Indium-Tris-Guanidinates: A Promising Class of Precursors for Water Assisted Atomic Layer Deposition of In2O3 Thin Films. Dalt. Trans. 2014, 43, 937-940.

(24) Barry, S. T.; Gordon, P. G.; Ward, M. J.; Heikkila, M. J.; Monillas, W. H.; Yap, G. P. A.; Ritala, M.; Leskelä, M. Chemical Vapour Deposition of In2O3 Thin Films from a Tris-Guanidinate Indium Precursor. Dalt. Trans. 2011, 40, 9425-9430.

(25) Brazeau, A. L.; DiLabio, G. A.; Kreisel, K. A.; Monillas, W.; Yap, G. P. A.; Barry, S. T. Theoretical and Experimental Investigations of Ligand Exchange in Guanidinate Ligand Systems for Group 13 Metals. J. Chem. Soc. Dalt. Trans. 2007, No. 30, 3297-3304.

(26) Kenney, A. P.; Yap, G. P. A.; Richeson, D. S.; Barry, S. T. The Insertion of Carbodiimides into $\mathrm{Al}$ and $\mathrm{Ga}$ Amido Linkages. Guanidinates and Mixed Amido Guanidinates of Aluminum and Gallium. Inorg. Chem. 2005, 44, 2926-2933.
(27) Brazeau, A. L.; Wang, Z.; Rowley, C. N.; Barry, S. T. Synthesis and Thermolysis of Aluminum Amidinates: A Ligand-Exchange Route for New Mixed-Ligand Systems. Inorg. Chem. 2006, 45, 2276-2281.

(28) Leman, J. T.; Barron, A. R. Synthesis of 1,3-Diphenyltriazenide Complexes of Aluminium, Gallium and Indium: Crystal Structure of Tris(1,3-Diphenyltriazenido)Aluminium(III). Polyhedron 1989, 8, 1909-1912.

(29) Leman, J. T.; Braddock-Wilking, J.; Coolong, A. J.; Barron, A. R. 1,3-Diaryltriazenido Compounds of Aluminum. Inorg. Chem. 1993, 32, 4324-4336.

(30) O’Brien, N. J.; Rouf, P.; Samii, R.; Rönnby, K.; Buttera, S. C.; Hsu, C.-W.; Ivanov, I. G.; Kessler, V.; Ojamäe, L.; Pedersen, H. InSitu Activation of an Indium(III) Triazenide Precursor for Epitaxial Indium Nitride by Atomic Layer Deposition. Chem. Mater. 2020, 32, 4481-4489.

(31) Rouf, P.; Samii, R.; Rönnby, K.; Bakhit, B.; Buttera, S. C.; Martinovic, I.; Ojamäe, L.; Hsu, C.-W.; Palisaitis, J.; Kessler, V.; Pedersen, H.; O’Brien, N. J. Hexacoordinated Gallium(III) Triazenide Precursor for Epitaxial Gallium Nitride by Atomic Layer Deposition. ChemRxiv 2020, DOI: 10.26434/chemrxiv.13190636.v1.

(32) Bottaro, J. C.; Penwell, P. E.; Schmitt, R. J. Expedient Synthesis of T-Butyl Azide. Synth. Commun. 1997, 27, 1465-1467.

(33) Swetha, M.; Ramana, P. V.; Shirodkar, S. G. Simple and Efficient Method for the Synthesis of Azides in Water-THF Solvent System. Org. Prep. Proced. Int. 2011, 43, 348-353.

(34) Mayo, D. H.; Peng, Y.; Zavalij, P.; Bowen, K. H.; Eichhorn, B. W. Aluminium(III) Amidinates Formed from Reactions of "AlCl" with Lithium Amidinates. Acta Crystallogr., Sect. C: Cryst. Struct. Commun. 2013, 69, 1120-1123.

(35) Springer Jr, C. S.; Sievers, R. E. Intramolecular Isomerization of Octahedral Complexes by Mechanisms Not Involving Bond Rupture. Inorg. Chem. 1967, 6, 852-854.

(36) Rodger, A.; Johnson, B. F. Which Is More Likely: The Ray-Dutt Twist or the Bailar Twist? Inorg. Chem. 1988, 27, 3061-3062.

(37) Bryant, R. G. The NMR Time Scale. J. Chem. Educ. 1983, 60, 933-935.

(38) Kunte, G. V.; Shivashankar, S. A.; Umarji, A. M. Thermogravimetric Evaluation of the Suitability of Precursors for MOCVD. Meas. Sci. Technol. 2008, 19, 025704.

(39) Colominas, C.; Lau, K. H.; Hildenbrand, D. L.; Crouch-Baker, S.; Sanjurjo, A. Vapor Pressures of the Copper and Yttrium $\beta$ Diketonate MOCVD Precursors. J. Chem. Eng. Data 2001, 46, 446450.

(40) Frisch, M. J.; Trucks, G. W.; Schlegel, H. B.; Scuseria, G. E.; Robb, M. A.; Cheeseman, J. R.; Scalmani, G.; Barone, V.; Petersson, G. A.; Nakatsuji, H.; Li, X.; Caricato, M.; Marenich, A. V.; Bloino, J.; Janesko, B. G.; Gomperts, R.; Mennucci, B.; Hratchian, H. P.; Ortiz, J. V.; Izmaylov, A. F.; Sonnenberg, J. L.; Williams-Young, D.; Ding, F.; Lipparini, F.; Egidi, F.; Goings, J.; Peng, B.; Petrone, A.; Henderson, T.; Ranasinghe, D.; Zakrzewski, V. G.; Gao, J.; Rega, N.; Zheng, G.; Liang, W.; Hada, M.; Ehara, M.; Toyota, K.; Fukuda, R.; Hasegawa, J.; Ishida, M.; Nakajima, T.; Honda, Y.; Kitao, O.; Nakai, H.; Vreven, T.; Throssell, K.; Montgomery, J. A., Jr.; Peralta, J. E.; Ogliaro, F.; Bearpark, M.; Heyd, J. J.; Brothers, E. N.; Kudin, K. N.; Staroverov, V. N.; Kobayashi, R.; Normand, J.; Raghavachari, K.; Rendell, A.; Burant, J. C.; Iyengar, S. S.; Tomasi, J.; Cossi, M.; Millam, J. M.; Klene, M.; Adamo, C.; Cammi, R.; Ochterski, J. W.; Martin, R. L.; Morokuma, K.; Farkas, O.; Foresman, J. B.; Fox, D. J. Gaussian 16, revision B.01; Gaussian, Inc.: Wallingford CT, 2016.

(41) Hanson-Heine, M. W. D.; George, M. W.; Besley, N. A. Calculating Excited State Properties Using Kohn-Sham Density Functional Theory. J. Chem. Phys. 2013, 138, 064101.

(42) Lecklider, T. Evaluation Engineering: Maintaining a Healthy Rhythm, 2011. https://www.evaluationengineering.com/home/ article/13005576/maintaining-a-healthy-rhythm.

(43) Grimme, S.; Antony, J.; Ehrlich, S.; Krieg, H. A Consistent and Accurate $\mathrm{Ab}$ Initio Parametrization of Density Functional Dispersion Correction (DFT-D) for the 94 Elements H-Pu. J. Chem. Phys. 2010, $132,154104$. 
(44) Weigend, F.; Ahlrichs, R. Balanced Basis Sets of Split Valence, Triple Zeta Valence and Quadruple Zeta Valence Quality for $\mathrm{H}$ to Rn: Design and Assessment of Accuracy. Phys. Chem. Chem. Phys. 2005, 7, 3297-3305.

(45) Metz, B.; Stoll, H.; Dolg, M. Small-Core MulticonfigurationDirac-Hartree-Fock-Adjusted Pseudopotentials for Post-d Main Group Elements: Application to $\mathrm{PhB}$ and $\mathrm{PbO}$. J. Chem. Phys. 2000, 113, 2563-2569. 